\title{
Application of Electrocoagulation and Electrolysis on the Precipitation of Heavy Metals and Particulate Solids in Washwater from the Soil Washing
}

Ho Y. Shim, Kyo S. Lee, Dong S. Lee, Dae S. Jeon, Mi S. Park, Ji S. Shin, Yun K. Lee, Ji W. Goo, Soo B. Kim, Doug Y. Chung*

Department of Bio-Environmental Chemistry, College of Agriculture and Life Science, Chungnam National University, Daejeon, Korea

Email: ${ }^{*}$ dychung@cnu.ac.kr

Received 28 August 2014; revised 29 September 2014; accepted 7 October 2014

Copyright (C) 2014 by authors and Scientific Research Publishing Inc.

This work is licensed under the Creative Commons Attribution International License (CC BY).

http://creativecommons.org/licenses/by/4.0/

(c) (i) Open Access

\section{Abstract}

Soil washing, ex situ mechanical technique, is one of the few permanent treatment alternatives to remove metal contaminants from soils by employing physical separation based on mineral processing technologies to remove discrete particles or metal-bearing particles and/or chemical extraction based on leaching or dissolving process to extract the metals from the soils into an aqueous solution. However, washwater remained from soil washing process contains discrete particulate particles along with heavy metals as solution phase to be treated separately, as well as this process can produce large amount of sludge that requires further treatment, slow metal precipitation, poor settling, the aggregation of metal precipitates. Electrical treatments including electrocoagulation and electrolysis can be effective in removing these substances from washwater. This paper reviews the theoretical models in applying electrocoagulation and electrolysis to remove heavy metals and discrete particulate particles in washwater by examining and comparing the status of washwater treatment technologies which have been undertaken, mostly in the US and EU for the period 1990-2012.

\section{Keywords}

Electrocoagulation, Electrolysis, Precipitation, Heavy Metals, Washwater, Soil Washing

\footnotetext{
${ }^{*}$ Corresponding author.

How to cite this paper: Shim, H.Y., et al. (2014) Application of Electrocoagulation and Electrolysis on the Precipitation of Heavy Metals and Particulate Solids in Washwater from the Soil Washing. Journal of Agricultural Chemistry and Environment, 3, 130-138. http://dx.doi.org/10.4236/jacen.2014.34015
} 


\section{Introduction}

Unlike organic contaminants, heavy metals which are known to be toxic or carcinogenic tend to accumulate in living organisms because they are not biodegradable. Due to their high solubility in the aquatic environments, heavy metals can be absorbed by living organisms. Therefore, it is necessary to treat metal contaminated wastewater and soils prior to its discharge to the environment to protect the people and the environment [1]. Many methods that are being used to remove heavy metal ions include chemical precipitation, ion-exchange, adsorption, membrane filtration, electrochemical treatment technologies, etc.

Soil washing that is ex situ mechanical techniques to extract metals contaminants from soils employs physical separation based on mineral processing technologies and/or chemical extraction based on leaching or dissolving process [2]. Soil washing uses washing solution that may be simply water or may it may be water-containing additives, such as detergent or acid liquids to remove chemical pollutants which usually adhere to the surfaces of the silt or clay particles rather than to the sand or gravel particles.

Physical separation technique is primarily applicable to particulate forms of metals such as discrete particles or metal-bearing particles, concentrate metal contaminants into a smaller volume of soil by exploiting differences in certain physical characteristics between the metal bearing particles and soil particles (size, density, magnetism, and hydrophobic surface properties) [3] [4]. The difficulties of physical separation in soil washing treatment are as follows: 1) the metal contaminants are strongly bound on soil particles; 2) the difference in density or surface properties between metal-bearing particles and soil matrix are not significant; 3) high variability of chemical forms of metals; 4) the metals are present in all particle size fractions of contaminated soil; 5) the soil contains silt/clay content in excess of 30\% - 50\%; 6) the soil contains high humic content; and 7) the soil contains organic compounds with high viscosity [5].

Gravity concentration techniques exploit the difference in gravity of particles in slurry to separate the metal-bearing particles from soil matrix. However, gravity separation is inefficient when used to treat particles that have either a wide size distribution or a narrow density distribution. The gravity concentration technologies should therefore be particularly suitable for particle separation when the density difference between the soil and contaminant particles is significant [4].

Chemical extraction relates to techniques that try to solubilize the metal contaminants from the soil with an extracting aqueous fluid containing chemical reagents such as acids or chelating agents. Heavy metals on the washwater and various soil fractions which are usually separated by gravity settling can be removed by conventional treatment processes such as chemical precipitation, ion exchange, and electrochemical removal. However, chemical precipitation that is the most widely used for heavy metal removal from inorganic effluent is not economical and can produce large amount of sludge that requires further treatment, slow metal precipitation, poor settling, the aggregation of metal precipitates [6]. Therefore, we need to develop the new technology to treat washwater remained from soil washing method.

Thus, the difficulties in soil washing during remediation of the heavy metal contaminated soils are properly to treat washwater containing discrete fine soil particles with heavy metals and heavy metals as soil solution phase. This paper is to present a brief methodology and principles to remove heavy metals and discrete soil particles in washwater during soil washing for soil contaminated with heavy metals.

\section{Applicable Technologies for the Treatments of Washwater from Soil Washing}

Different treatment techniques have been used to remove discrete particulate particles and heavy metals in wastewater and to improve the quality of the treated washwater. Although various kinds of physical separation technologies and chemical treatments such as chemical precipitation, coagulation-flocculation, flotation, ion exchange and membrane filtration have been employed, they have their inherent advantages and limitations in application.

A colloid, the most difficult discrete solids to remove from washing solution, is very small, finely divided solid particles that remain dispersed in a liquid for a long time due to their small size and electrical charge, as well as their small mass having a low gravitational force compared to surface frictional forces. Most particles dissolved in water have a negative charge and tend to repel each other, resulting in that they stay dispersed and dissolved or colloidal in the water.

Heavy metals in washwater from soil washing may be found in one or more of the following forms: 1) dissolved (in soil washing solution), 2) exchangeable in organic and inorganic components, 3) as structural com- 
ponents of the lattices of soil minerals, 4) as insoluble precipitates with other soil components.

Liberation degree depending on the mineralogical aspects of metal contaminant particles such as shape, morphology, and mineralogical association refers to the release availability of the metal phase referring to the mineral form in the presence of the metal according to various associations with the "carrying phase" referring another mineral phase such as Fe-oxides, carbonates, silicates, etc. associated with the metal phase or the soil particles as shown in Figure 1 [5].

\subsection{Physical Separation}

Physical separation techniques are primarily applicable to particulate forms of metals: discrete particles or metal-bearing particles [5]. The efficiency of physical separation depends on various soil characteristics such as particle size distribution, particulate shape, clay content, moisture content, humic content, heterogeneity of soil matrix, difference in density between soil matrix and metal contaminants, magnetic properties, and hydrophobic properties of particle surface [3] [4]. However, this technique is difficult or unfeasible for the following cases [5]: 1) the metal-bearing particles; 2) the difference in density or surface properties between metal-bearing particles; 3) high variability of chemical forms of metals; 4) the metals are present in all particle size fractions of soil; 5) the excessive content of clay-sized silt and clay; 6) high humic content; and 7) the soil organic matter with high viscosity.

In soil washing, physical separation of which units are generally consisted of mechanical screening, hydrodynamic classification, gravity concentration, froth flotation, magnetic separation, electrostatic separation, and attrition scrubbing is primarily applicable when metal contaminants are under particulate forms, while it is generally not appropriate for treating the sorbed forms of metals although attrition scrubbing can significantly improve metal desorption in chemical leaching process [5].

\subsection{Chemical Treatments}

The conventional chemical processes for removing heavy metals from wastewater include many processes such as chemical precipitation, flotation, adsorption, ion exchange, and electrochemical deposition. Factors that may limit the applicability and effectiveness of the chemical process include: 1) high clay/silt content; 2) high humic content; 3) high content of Fe and Ca element; 4) high calcite content or high buffering capacity; 5) simultaneous contamination of both cationic or anionic heavy metals; 6) high heterogeneity of soil; and 7) metals associated with residual soil fraction, imbedded in the mineral lattices, or discrete particle forms [7] [8].

\section{Chemical Precipitation}

Chemical precipitation is effective and cost-saving process for heavy metals removal from aqueous solutions and by far the most widely used process in industry because it is relatively simple to operate [9]. In the precipitation process that can generate very fine particles that are held in suspension by electrostatic surface charges, chemical precipitants, coagulants, and flocculation are used to increase particle size through aggregation, resulting in production of large amount of sludge to be treated with great difficulties [7]-[10]. However, this is usually effective to treat high concentration wastewater containing heavy metal ions and [8].

1) Hydroxide Precipitation

The conventional chemical precipitation processes in which chemicals react with heavy metal ions to form insoluble precipitates include hydroxide precipitation and sulfide precipitation. The conceptual mechanism of heavy metal removal by hydroxide precipitation is presented in (1) [11].

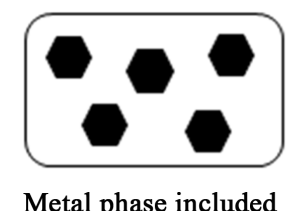
in volume

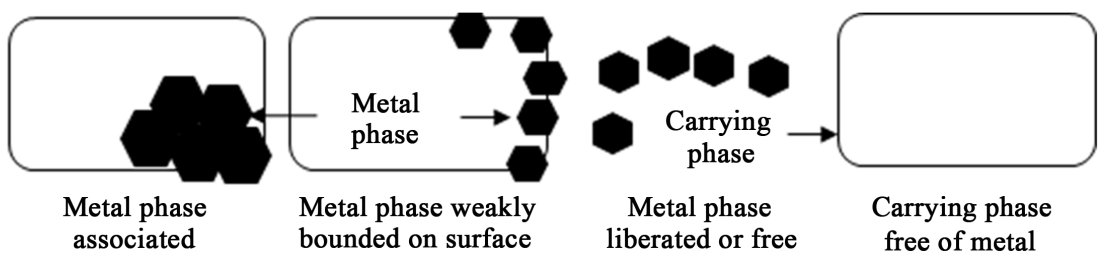

Figure 1. Applicability of physical separation according to liberation degree of the metal phase for the particulate forms. 


$$
\mathrm{M}^{2+}+2 \mathrm{OH}^{-} \leftrightarrow \mathrm{M}(\mathrm{OH})_{2} \downarrow
$$

where $\mathrm{M}^{2+}$ and $\mathrm{OH}^{-}$represent the dissolved metal ions and the precipitant, respectively, while $\mathrm{M}(\mathrm{OH})_{2}$ is the insoluble metal hydroxide. Adjustment of $\mathrm{pH}$ to the basic conditions ( $\mathrm{pH} 9$ - 11) may significantly improves heavy metal removal by chemical precipitation.

In hydroxide precipitation process, the addition of coagulants such as alum, iron salts, and organic polymers can enhance the removal of heavy metals from wastewater. However, hydroxide precipitation generates large volumes of relatively low density sludge, as well as it takes a long time for the tiny particles dispersed in the solution to settle down prior to the addition of the coagulant aid to the solutions [12]. Also the mixed metals which are amphoteric create a problem using hydroxide precipitation since the ideal $\mathrm{pH}$ for one metal may put another metal back into solution, and complexing agents in the wastewater will inhibit metal hydroxide precipitation [8].

2) Sulfide Precipitation

The Metal sulfides are typically very insoluble. Therefore metals can be precipitated by adding sulfide ions $\left(\mathrm{S}^{2-}\right)$. Hence, an equilibrium is generated resulting in only the partial formation of the $\mathrm{S}^{2-}$ ions actually used in precipitation by adding a sulfide salt because $\mathrm{S}^{2-}$ is not the dominating species until the $\mathrm{pH}$ is very high ( 14). Sulfide precipitates tend to form colloidal particles requiring the addition of coagulants to settle. Assuming that an aqueous solution of $\mathrm{S}^{2-}$ contains a reasonable concentration of $\mathrm{H}_{2} \mathrm{~S}$, a balanced equation for the reaction of a metal ion with sulfide in a neutral or acidic solution, as in (2) [13]-[15].

$$
\mathrm{M}^{2+}(\mathrm{aq})+\mathrm{H}_{2} \mathrm{~S}(\mathrm{aq})+2 \mathrm{H}_{2} \mathrm{O}(\mathrm{l}) \leftrightarrows \mathrm{MS}(\mathrm{s})+2 \mathrm{H}_{3} \mathrm{O}^{+}(\mathrm{aq})
$$

where $\mathrm{M}^{2+}$ represents the dissolved metal ions, while MS(s) is the insoluble metal sulfide.

Heavy metal ions often in acid conditions and sulfide precipitant in acidic conditions can result in the evolution of toxic $\mathrm{H}_{2} \mathrm{~S}$ fumes. Moreover, metal sulfide precipitation tends to form colloidal precipitates that cause some separation problems in either settling or filtration processes [8].

3) Coagulation and Flocculation

The coagulation-flocculation mechanism is proposed based on zeta potential ( $\zeta$ ) measurement as the criteria to define the electrostatic interaction between pollutants and coagulant-flocculant agents [16]. Coagulation that is brought about by the reduction of the net surface charge of the colloidal particles to a point where the stabilized colloidal particles by electrostatic repulsion can approach closely enough for vander Waals forces to hold them together and allow aggregation is the destabilization of colloids by charge neutralization of particles and by enmeshment of the impurities on the formed amorphous metal hydroxide precipitates [17]. Coagulants with charges opposite to those of the discrete solids are added to the water to neutralize the negative charges on dispersed non-settable solids such as clay and organic substances [18].

The reduction of the surface charge is a result of the decrease of the repulsive potential of the electrical double layer by the presence of an electrolyte having opposite charge. Once charged, the particles bond together like small magnets to form a mass. Therefore, the addition of chemical coagulants which is followed by low-sheer mixing in a flocculator to promote contact between the particles are often to overcome the repulsive forces of the particles [19].

Flocculation, a gentle mixing stage to form bridges between the flocs and bind the particles, continually increases the particle size to grow submicroscopic microfloc to visible discrete particles through additional collisions and interaction with inorganic polymers formed by the coagulant or with organic polymers added [20]. Once discrete particles are flocculated into larger particles, they can usually be removed or separated by filtration, straining or floatation. Disadvantages are input of chemicals required and transfer of toxic compounds into solid phase and formation of sludge that has to be treated subsequently.

\subsection{Electrochemical Treatments}

The Using electricity to treat water was first proposed in UK in 1889 and the application of electrolysis in mineral beneficiation was patented by Elmore in 1904 [21]. Electrochemistry is the chemical reactions which take place at the interface of an electrode: usually a solid metal or a semiconductor and an ionic conductor, the electrolyte. In electrochemistry, electricity can be generated by movements of electrons from one element to another in a reaction known as a redox reaction or oxidation-reduction reaction. When a chemical reaction is caused by an externally supplied current, as in electrolysis, or if an electrical current is produced by a spontaneous chemical reaction [22]. 
Electrochemical process to treat washwater containing heavy metals is to precipitate the heavy metals in a stationary, weak acidic or neutralized catholyte as hydroxides. Electrochemical treatments of washwater involve electrodeposition, electrocoagulation, electroflotation and electrooxidation [23]. These processes can be simulated by a two-stage procedures. At stage 1, the acid process water containing metal passed through the cathode chamber. In this case, the $\mathrm{pH}$ was increased by the production of free $\mathrm{OH}$ ions as shown in (3) and metal hydroxides may be precipitated and/or noble metals may be deposited in their pure form (4):

$$
\begin{gathered}
4 \mathrm{H}_{2} \mathrm{O}+4 \mathrm{e}^{-} \rightarrow 2 \mathrm{H}_{2}+4 \mathrm{OH}^{-} \\
\mathrm{Me}^{n+}+n \mathrm{OH}^{-} \rightarrow \mathrm{Me}(\mathrm{OH})_{n}(\mathrm{~s})
\end{gathered}
$$

\section{Chemical Precipitation}

The electrocoagulation process using electrical energy, similar to the typical physical and chemical treatments of emulsified oil, total petroleum hydrocarbons, discrete solids, and heavy metals, is the electrochemical production of destabilization agents such as $\mathrm{Al}$ and $\mathrm{Fe}$ that bring about neutralization of electric charge to remove pollutant that are not easy to remove by filtration or chemical treatment systems.

In the EC process, the coagulant is generated in situ by electrolytic oxidation of an appropriate anode material. In this process, charged ionic metal species are removed from wastewater by allowing it to react with anion having an opposite charge, or with floc of metallic hydroxides generated within the effluent. This process is characterized by reduced sludge production, no requirement for chemical use, and ease of operation. Colloiddestabilizing agents that effect on-charge neutralization are produced by electrolysis in the electrocoagulation process [24] [25]. Holt et al. [26] [27] reported that there were three operating stages in the removal of clay particles or colloidal matters by EC: i) lag where no significant change in clay removal takes place; ii) reactive stage in which most of clay removal occurs and finally iii) stable stage where clay removal is approximately constant.

Mollah et al. (2001) [25] and Canizares et al. (2010) [28] indicated that the main mechanisms responsible for the clay or colloidal matters removal during EC are:

1) Charge neutralization of negatively charged particles of the clay particles through the electrophoresis migration of those particles towards the anode under the influence of electrical field.

2) Charge neutralization of the negatively charged clay particles by adsorption of monomeric and polymeric hydrolysis species of $\mathrm{Al}^{3+}$.

3) The charge neutralized clay particles coalesce upon collision as a result of their Brownian movement or their electrophoretic migration to form a larger floc which can be easily removed.

4) Sweep flocculation which takes place as the $\mathrm{Al}(\mathrm{OH})_{3}$ reaches its minimum solubility and precipitates and during its precipitation clay particles may be enmeshed between $\mathrm{Al}(\mathrm{OH})_{3}$ and removed from the bulk.

5) The coalesced clay particles may adhere to $\mathrm{H}_{2}$ bubbles generated at the cathode and float to the surface and can be easily removed.

All the above mechanisms can contribute in the removal of clay particles during reactive stages. However, the concentration of clay particles may decreases and charge neutralization through electrophoretic migration can also diminishes during stable stage; on the other hand the $\mathrm{pH}$ reaches neutrality with precipitation of $\mathrm{Al}(\mathrm{OH})_{3}$ [26].

\section{Theoretical Backgrounds for Precipitation of Heavy Metals and Particulate Solids in Washwater}

The effective colloid removal is to reduce the zeta potential with coagulants, such as alum, ferric chloride and/or cationic polymers for formation of floc particles that settle rapidly and filter easily [29]. Flocculation of the discrete particles into larger particles will be removed from the liquid by sedimentation if a sufficient density difference exists between the discrete matter and the liquid.

Discrete particles have an electric surface charge on which an external electric field exerts an electrostatic Coulomb force [30]. The electric field also exerts a force on the ions in the diffuse layer which has direction opposite to that acting on the surface charge. This latter force is not actually applied to the particle, but to the ions in the diffuse layer located at some distance from the particle surface, and part of it is transferred all the way to the particle surface through viscous stress [31]. 
Zeta potential ( $\zeta$ ), a key indicator of the stability of colloidal dispersions, is defined as the electrical potential developed by the accumulation of ions at the surface of the colloidal particle in response to the relative movement of soil particles and water. Also it can be interpreted as the potential difference between the dispersion medium and the stationary layer of fluid attached to the dispersed particle. It's with this charge that the colloid interacts with other colloids.

The magnitude of the zeta potential indicates the degree of electrostatic repulsion between adjacent, similarly charged particles in a dispersion. Van der Waal's forces, the tendency of particles in nature to attract each other weakly, make the particles join together into floc which becomes to settle out of the water. Removing the repulsive forces allows them to form large flocs that can be settled fast and filtered easily. When the potential is small, attractive forces may exceed this repulsion and the dispersion may break and flocculate. So, colloids with high zeta potential (negative or positive) are electrically stabilized while colloids with low zeta potentials tend to coagulate or flocculate [32] (Figure 2).

The zeta potentials of clays are $\mathrm{pH}$ dependent and that the $\mathrm{pH}$ of the system varies between anode and cathode during the process. This is because, when a direct current is applied to a clayey soil, the electrolysis reactions that produce $\mathrm{O}_{2}$ at the anode and $\mathrm{H}_{2}$ at the cathode are as following (5) and (6) [33]:

$$
\begin{aligned}
& 2 \mathrm{H}_{2} \mathrm{O}-4 \mathrm{e}^{-} \rightarrow \mathrm{O}_{2} \uparrow+4 \mathrm{H}^{+} \text {at anode } \\
& 2 \mathrm{H}_{2} \mathrm{O}+2 \mathrm{e}^{-} \rightarrow \mathrm{H}_{2}+2 \mathrm{OH}^{-} \text {at cathode }
\end{aligned}
$$

As a result of the described electrolysis reaction in (4) and (5), the $\mathrm{pH}$ increases at the cathode and decreases at the anode, resulting in the potential becoming less negative near the anode and more negative near the cathode.

Electrolysis is a process to break substances apart by using electricity in the separation of elements from naturally occurring sources [22]. The key process of electrolysis by which electric current is passed through a substance to effect a chemical change is the interchange of atoms and ions by the removal or addition of electrons from the external circuit. The substance to be transformed may form the electrode, may constitute the solution, or may be dissolved in the solution [34]. The released ions neutralize the charges of the particles and thereby in-

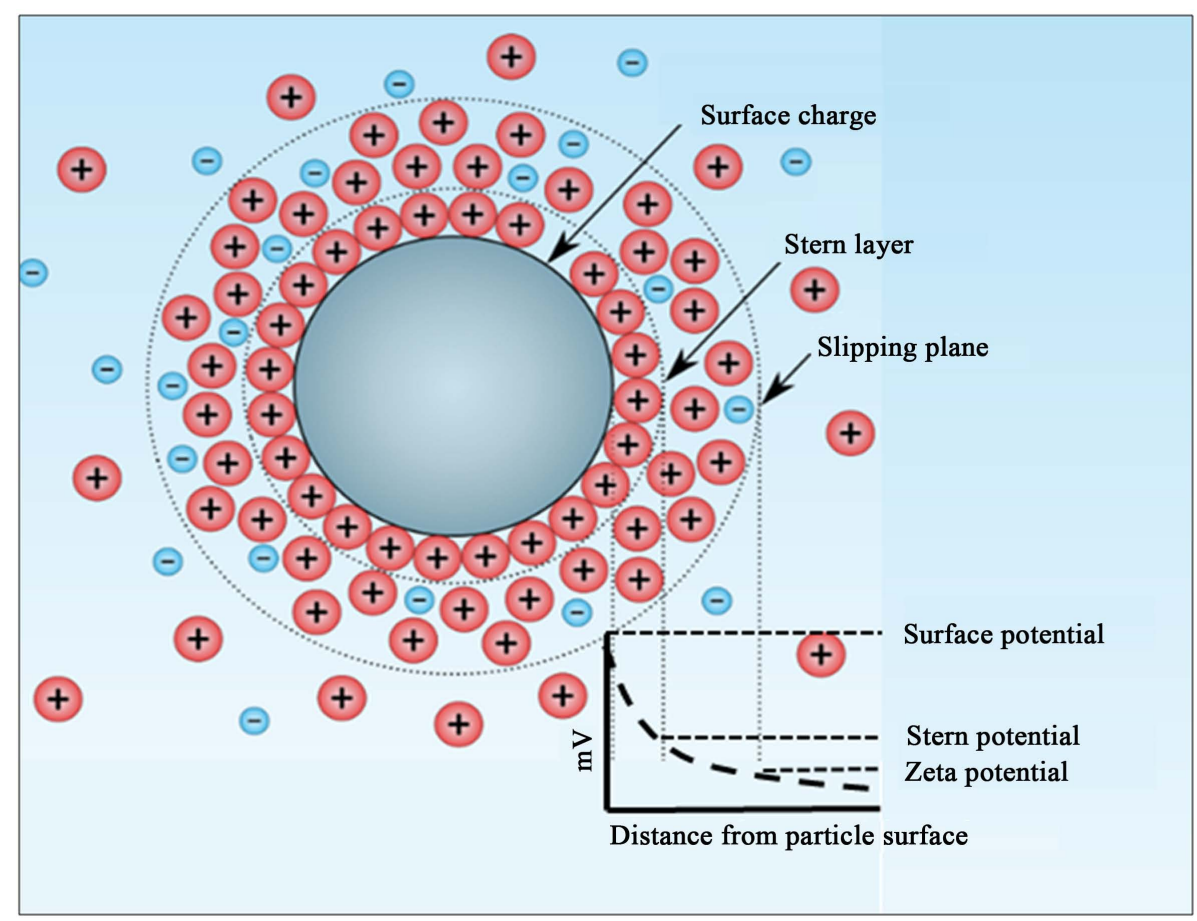

Figure 2. Diagram showing the ionic concentration and potential difference as a function of distance from the charged surface of a particle discrete in a dispersion medium (from Wikipedia, the free encyclopedia). 
itiate coagulation, and may remove the undesirable contaminants either by chemical reaction and precipitation, or by causing the colloidal materials to coalesce and then removed by electrolytic flotation [25]. The results of electrolysis time on rate of clay removal at different current densities showed that the clay removal increases rapidly to reach to maximum in reactive stage then it approaches almost a constant removal rate in stable stage, while increase in concentration of electrolytes lowered the clay removal [35]-[37].

\section{New Concept of Washwater Treatment System Using Electrocoagulation and Electrodeposition}

As seen above, the washwater remained from soil washing process contains discrete particulate particles including metal-bearing particles or soluble heavy metals as solution phase. Gravity forces will not cause precipitation of these colloidal particles and heavy metals in washwater because the suspension is generally stable and heavy metals are not neutralized. So they need special treatment to remove them from the aqueous phase. To remove these substances through precipitation from the washwater, it requires to bring the suspended discrete particulate particles together so they will form larger more settleable clumps called floc and also needs to precipitate the heavy metals by adding chemicals such as hydroxide, sulfide ions or inorganic carbonates to form insoluble precipitates.

New concept is to remove the discrete particulate particles including metal-bearing particles or soluble heavy metals in washwater by applying the principles of electrochemistry including electrocoagulation and electrodeposition by addition of hydroxide and electrons produced from anode and cathode as shown in Figure 3 . The destabilization of colloids is called coagulation and precipitation by hydroxide formation to acceptable levels is the most common heavy metal precipitation method.

EC is the electrochemical production of destabilization agents that brings about charge neutralization of negative charged surfaces of colloidal or discrete particles. EC process involves three successive stages: a) formation of coagulants by electrolytic oxidation of the "sacrificial electrode"; b) destabilization of the contaminants, particulate suspension, and breaking of emulsions; c) aggregation of the destabilized phases to form flocs. The destabilization mechanism of the contaminants, particulate suspension, and breaking of emulsions has been described in broad steps and may be summarized as follows [25]:

1) Compression of the diffuse double-layer around the charged species, which is achieved by the interactions of ions generated by dissolution of the sacrificial electrode, due to passage of current through the solution.

2) Charge neutralization of the ionic species present in wastewater, which is caused by the counter ions, produced by the electrochemical dissolution of the sacrificial electrode. These counter ions reduce the electrostatic interparticle repulsion sufficiently so that the vander Waals attraction predominates, thus causing coagulation. A zero net charge results in the process.

3) Floc formation, and the floc formed as a result of coagulation creates a sludge blanket that entraps and bridges colloidal particles that have not been complexed.

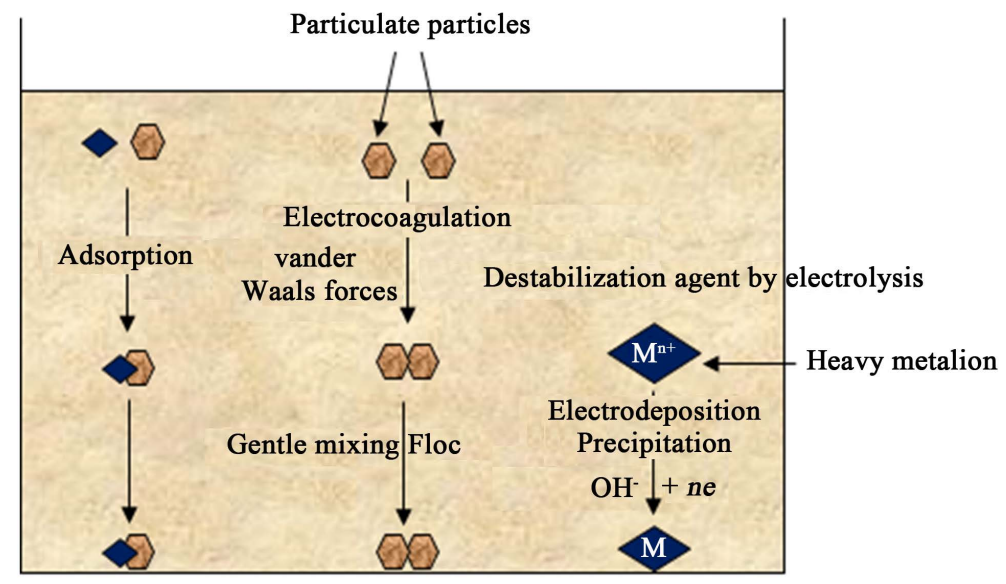

Figure 3. Simplified scheme of washwater treatment system using electrocoagulation and electrolysis on precipitation of heavy metals and particulate solids in washwater. 
The EC process is as follows:

At the anode,

$$
\mathrm{M} \rightarrow \mathrm{M}^{n+}+n \mathrm{e}^{-}
$$

Water electrolysis at the cathode,

$$
n \mathrm{H}_{2} \mathrm{O}+n \mathrm{e}^{-} \rightarrow \mathrm{H}_{2}+n \mathrm{OH}^{-}
$$

where, $\mathrm{M}=$ anode material and $n=$ number of electrons involved in the oxidation/reduction reaction.

Ions of soluble metals such as $\mathrm{Al}$ and $\mathrm{Fe}$ are generated at the anode and react with the hydroxide ions formed at the cathode, and the metal hydroxides are produced as expressed (8).

$$
\mathrm{M}^{n+}+n \mathrm{OH}^{-} \rightarrow \mathrm{M}(\mathrm{OH})_{n}
$$

These insoluble metal hydroxides react with the discrete and/or colloid solids and precipitate.

\section{Conclusion}

The discrete particulate particles including metal-bearing particles or soluble heavy metals as solution phase in washwater remained from soil washing process will not be easily removed because the suspension is generally stable and heavy metals are not neutralized. So they need special treatment to remove them from the aqueous phase. Removal of these discrete particulate particles including metal-bearing particles or soluble heavy metals in washwater is to apply the principles of electrochemistry including electrocoagulation and electrodeposition to destabilize these discrete particulate particles to form larger settleable flocs and to immobilize heavy metals by hydroxide formation. From the economic and environmental point of view, application of electrocoagulation and electrodeposition by electrolysis may be an effective alternative to remove these discrete particulate particles including metal-bearing particles or soluble heavy metals in washwater. However, there appear to be several approaches that can be taken based on fundamental principles from the electrochemical perspective in aqueous phase.

\section{Acknowledgements}

This work was carried out with the support of "Cooperative Research Program for Agriculture Science \& Technology Development (Project No. PJ008516)” Rural Development Administration, Republic of Korea.

\section{References}

[1] Babel, S. and Kurniawan, T.A. (2004) Cr(VI) Removal from Synthetic Wastewater Using Coconut Shell Charcoal and Commercial Activated Carbon Modified with Oxidizing Agents and/or Chitosan. Chemosphere, 54, 951-967. http://dx.doi.org/10.1016/j.chemosphere.2003.10.001

[2] USEPA (1996) A Citizen’s Guide to Soil Washing. EPA/EPA 542-F-96-002.

[3] USEPA (1995) Contaminants and Remedial Options at Selected Metal-Contaminated Sites. EPA/540/R-95/512, Office of Research and Development, Washington DC.

[4] Williford, C.W. and Bricka, R.M. (2000) Physical Separation of Metal-Contaminated Soils. In: Iskandar, I.K., Ed., Environmental Restoration of Metals-Contaminated Soils, CRC Press LLC, Boca Raton, 121-165. http://dx.doi.org/10.1201/9781420026269.ch7

[5] Dermont, G., Bergeron, M., Mercier, G., Richer and Lafleche, M. (2008) Soil Washing for Metal Removal: A Review of Physical/Chemical Technologies and Field Applications. Journal of Hazardous Materials, 152, 1-31. http://dx.doi.org/10.1016/j.jhazmat.2007.10.043

[6] Barakat, M.A. (2011) New Trends in Removing Heavy Metals from Industrial Wastewater. Arabian Journal of Chemistry, 4, 361-377. http://dx.doi.org/10.1016/j.arabjc.2010.07.019

[7] USEPA (1980) Control and Treatment Technology for the Metal Finishing Industry: Sulfide Precipitation. EPA/625/ 8-80/003.

[8] Fu, F.L. and Wang, Q. (2011) Removal of Heavy Metal Ions from Wastewaters: A Review. Journal of Environmental Management, 92, 407-418. http://dx.doi.org/10.1016/j.jenvman.2010.11.011

[9] Ku, Y. and Jung, I.-L. (2001) Photocatalytic Reduction of Cr(VI) in Aqueous Solutions by UV Irradiation with the Presence of Titanium Dioxide. Water Research, 35, 135-142. http://dx.doi.org/10.1016/S0043-1354(00)00098-1

[10] USEPA (1990) Innovative and Alternative Technology Assessment Manual, EPA, Office of Water Program Operations. EPA/430/9-78/009. 
[11] Wang, L.K., Vaccari, D.A., Li, Y. and Shammas, N.K. (2004) Chemical Precipitation. In: Wang, L.K., Hung, Y.T. and Shammas, N.K., Eds., Physicochemical Treatment Processes, Vol. 3, Humana Press, New Jersey, 141-198.

[12] Kongsricharoern, N. and Polprasert, C. (1995) Electrochemical Precipitation of Chromium $\left(\mathrm{Cr}^{6+}\right)$ from an Electroplating Wastewater. Water Science and Technology, 31, 109-117. http://dx.doi.org/10.1016/0273-1223(95)00412-G

[13] Haas, C.N. and Vamos, R.J. (1995) Hazardous and Industrial Waste Treatment. Prentice Hall, Englewood Cliffs, 147152.

[14] Sundstrom, D.W. and Klei, H.E. (1979) Wastewater Treatment. Prentice Hall, Englewood Cliffs, 327-330.

[15] Wentz, C.W. (1995) Hazardous Waste Management. 2nd Edition, McGraw-Hill, New York, 155-157.

[16] López-Maldonado, E.A., Oropeza-Guzman, M.T., Jurado-Baizaval, J.L. and Ochoa-Terán, A. (2014) CoagulationFlocculation Mechanisms in Wastewater Treatment Plants through Zeta Potential Measurements. Journal of Hazardous Materials, 279, 1-10. http://dx.doi.org/10.1016/j.jhazmat.2014.06.025

[17] Benefield, L.D. Judkins, J.F. and Weand, B.L. (1982) Process Chemistry for Water and Wastewater Treatment. Prentice-Hall, Englewood Cliffs, 212.

[18] Firdaus, M.Y. (2013) Coagulation and Flocculation Process Fundamentals. http://muhammadyusuffirdaus.wordpress.com/2013/01/16/coagulation-and-flocculation-process-fundamentals/

[19] Federal Remediation Technologies Roundtable (1998) Remediation Case Studies: Innovative Groundwater Treatment Technologies. EPA/542/R-98/015.

[20] Tripathy, T. and De, B.R. (2006) Flocculation: A New Way to Treat the Waste Water. Journal of Physical Sciences, 10, 93-127.

[21] Chen, B., Qu, R., Shi, J., Li, D., Wei, Z., Yang, X. and Wang, Z. (2012) Heavy Metal and Phos-Phorus Removal from Water by Optimizing Use of Calcium Hydroxide and Risk Assessment. Environmental Pollution, 1, 38-54.

[22] Atkins, P. and De Paula, J. (2013) Physical Chemistry. 9th Edition, Oxford, 865-869.

[23] Hale, A.J. (2010) The Applications of Electrolysis in Chemical Industry. General Books LLC, New York.

[24] Rajeshwar, K. and Ibanez, J. (1997) Environmental Electrochemistry Fundamentals and Applications in Pollution Abatement. Academic Press, London.

[25] Mollah, M.Y.A., Schennach, R., Parga, J.R. and Cocke, D.L. (2001) Electrocoagulation (EC)—Science and Applications. Journal of Hazardous Materials, 84, 29-41. http://dx.doi.org/10.1016/S0304-3894(01)00176-5

[26] Holt, P., Barton, G., Wark, M. and Mitchell, C. (2002) A Quantitative Comparison between Chemical Dosing and Electrocoagulation. Colloids Surf A, 211, 233-248. http://dx.doi.org/10.1016/S0927-7757(02)00285-6

[27] Holt, P., Barton, G. and Mitchell, C. (2005) The Future for Electrocoagulation as a Localized Water Treatment Technology. Chemosphere, 59, 355-367. http://dx.doi.org/10.1016/j.chemosphere.2004.10.023

[28] Canizares, P., Martınez, F., Rodrigo, M., Jimenez, C. and Saez, C. (2008) Modeling of Wastewater Electrocoagulation Processes Part I. General Description and Application to Kaolin-Polluted Wastewaters. Separation and Purification Technology, 60, 155-161. http://dx.doi.org/10.1016/j.seppur.2007.08.003

[29] Lodhi, A.G. (2013) Zeta Potential. http://www.scribd.com/doc/134628605/Zeta-Potential-pdf

[30] Lyklema, J. (1995) Fundamentals of Interface and Colloid Science. Vol. 2, Academic Press, London.

[31] Hanaor, D.A.H., Michelazzi, M., Leonelli, C. and Sorrell, C.C. (2012) The Effects of Carboxylic Acids on the Aqueous Dispersion and Electrophoretic Deposition of $\mathrm{ZrO}_{2}$. Journal of the European Ceramic Society, 32, 235-244. http://dx.doi.org/10.1016/j.jeurceramsoc.2011.08.015

[32] Greenwood, R. and Kendall, K. (1999) Selection of Suitable Dispersants for Aqueous Suspensions of Zirconia and Titania Powders Using Acoustophoresis. Journal of the European Ceramic Society, 19, 479-488. http://dx.doi.org/10.1016/S0955-2219(98)00208-8

[33] Kaya, A. and Yukselen, Y. (2005) Zeta Potential of Clay Minerals and Quartz Contaminated by Heavy Metals. Canadian Geotechnical Journal, 42, 1280-1289. http://dx.doi.org/10.1139/t05-048

[34] Gesser, H.D. (2002) Applied Chemistry. Springer, Berlin, 16-55.

[35] Elsayed, E.M., Zewail, T.M. and Zaatout, A.A. (2013) Particulate Solids Removal from Synthetic and Real Turbid Water and Wastewater by Electro Coagulation Using Vertical Expanded Al Anode. Journal of Chemical Engineering Process Technology, 4, 177-183.

[36] Rahmani, A. (2008) Removal of Water Turbidity by the Electrocoagulation Method. Journal of Research in Health Science, 8, 18-24.

[37] Kilic, M. and Hosten, C. (2010) A Comparative Study of Electrocoagulation and Coagulation of Aqueous Suspensions of Kaolinite Powders. Journal of Hazardous Materials, 176, 735-740. http://dx.doi.org/10.1016/j.jhazmat.2009.11.097 
Scientific Research Publishing (SCIRP) is one of the largest Open Access journal publishers. It is currently publishing more than 200 open access, online, peer-reviewed journals covering a wide range of academic disciplines. SCIRP serves the worldwide academic communities and contributes to the progress and application of science with its publication.

Other selected journals from SCIRP are listed as below. Submit your manuscript to us via either submit@scirp.org or Online Submission Portal.
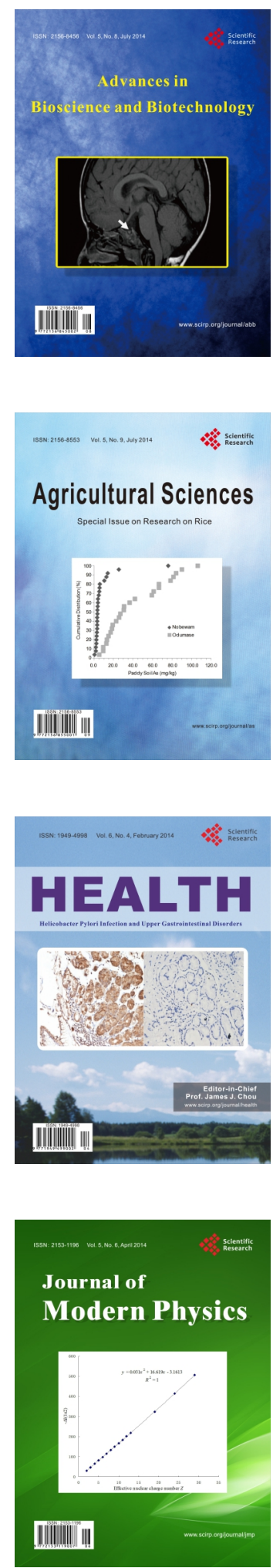
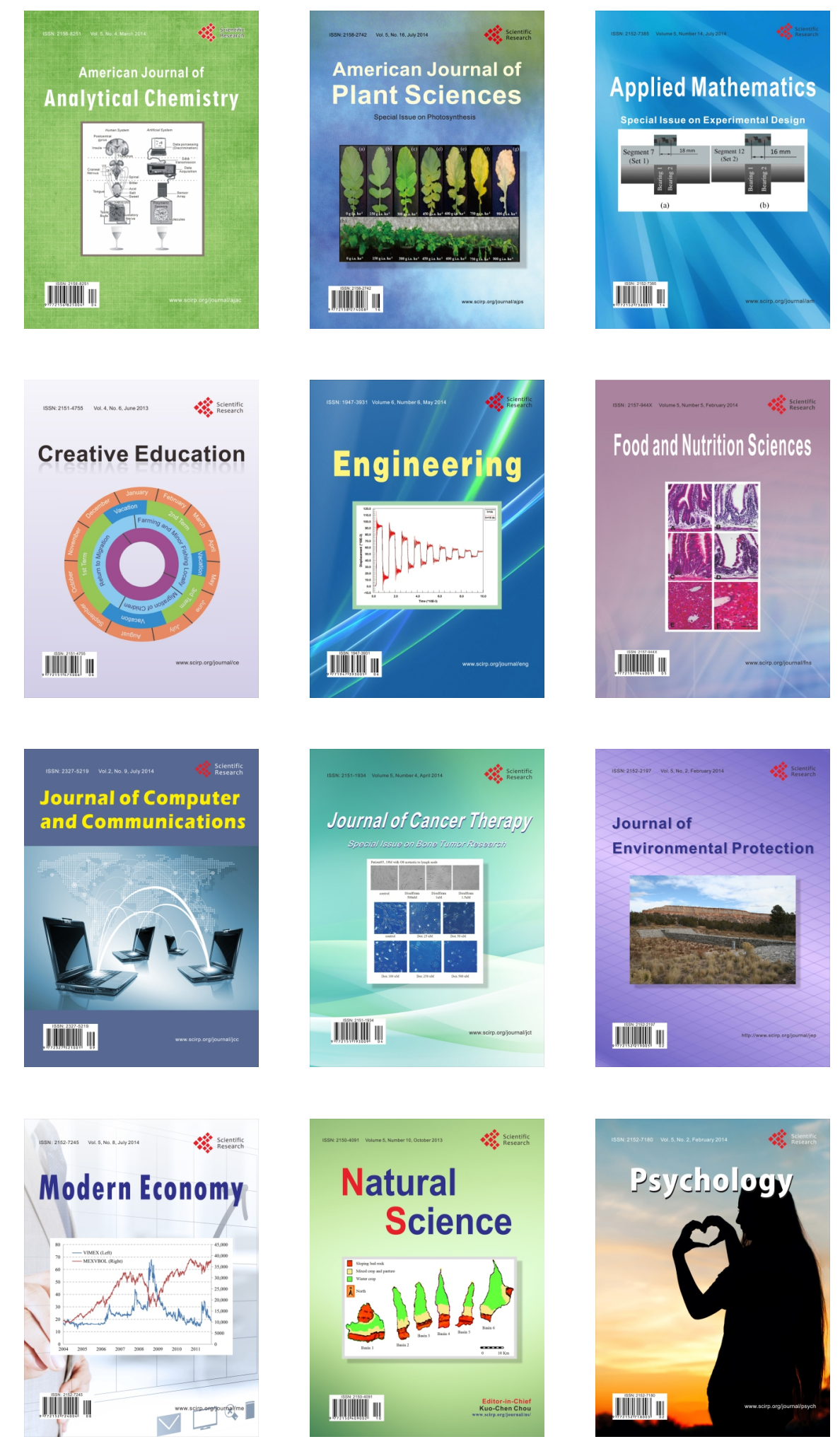